\title{
Antimicrobial peptides as an argument for the involvement of innate immunity in psoriasis (Review)
}

\author{
MIHAIL ALECU ${ }^{1,2^{*}}$, GABRIELA COMAN $^{1 *}$, ALINA MUSTETESCU $^{1,2^{*}}$ and OANA ANDREIA COMAN ${ }^{3}$ \\ ${ }^{1}$ Department of Dermatovenereology, 'Dr. Victor Babes' Clinical Hospital for Infectious and Tropical Diseases, \\ 030303 Bucharest; ${ }^{2}$ Departments of Dermatovenereology, Faculty of Medicine, 'Titu Maiorescu' University, \\ 040051 Bucharest; ${ }^{3}$ Department of Pharmacology and Pharmacotherapy, Faculty of Medicine, \\ 'Carol Davila' University of Medicine and Pharmacy, 050474 Bucharest, Romania
}

Received July 10, 2020; Accepted August 10, 2020

DOI: $10.3892 /$ etm.2020.9322

\begin{abstract}
Antimicrobial peptides (AMPs) are a group of oligopeptides found in most multicellular organisms with a capacity for rapid and nonspecific destruction of pathogens. The action of destroying pathogens is associated with a strong proinflammatory activity, stimulating the secretion of cytokines, chemokines, growth factors but also chemotaxis, the activation of dendritic cells and involving adaptive immunity also. The action of AMPs fits perfectly into the characteristics of innate immunity which makes these peptides candidates to be considered as an important element of this type of immunity. It has been shown that AMPs are involved in a number of cellular processes such as: differentiation, proliferation, maturation, thus widening the degree of involvement of these peptides in the pathogenesis of chronic inflammatory diseases. In psoriasis, AMPs act both as a pro-inflammatory and chemotaxis factor and through the cathelicidin (LL-37)/dc DNA complex as a possible autoantigen for T cells, triggering an autoimmune response, activating the Th17/IL23 axis and maintaining the inflammatory process. Thus, many arguments are accumulated to consider that innate immunity through AMPs is an important link in the pathogenesis of psoriasis. Moreover, the action of antimicrobial peptides in psoriasis is
\end{abstract}

Correspondence to: Professor Oana Andreia Coman, Department of Pharmacology and Pharmacotherapy, Faculty of Medicine, 'Carol Davila' University of Medicine and Pharmacy, 8 Eroilor Sanitari Avenue, 050474 Bucharest, Romania

E-mail: andreia.coman@gmail.com

*Contributed equally

Abbreviations: AMPs, antimicrobial peptides; LL-37, cathelicidin; TLR, Toll-like receptors; AP1, activator protein 1; NF- $\mathrm{BB}$, nuclear factor; RNase 7, ribonuclease 7; pDC, plasmacytoid dendritic cells; PAMP, pathogen associated molecular pattern

Key words: antimicrobial peptides, innate immunity, psoriasis, AMPs, defensin, psoriasin almost entirely characteristic for the general mode of action of innate immunity.

\section{Contents \\ 1. AMPs \\ 2. AMPs in innate immunity \\ 3. AMPs in psoriasis \\ 4. Conclusions}

\section{AMPs}

Antimicrobial peptides (AMPs) are oligopeptides with a variable number of amino acids, most commonly between 5 and 50 or 100 , with a direct and immediate activity on pathogens: Fungi, viruses and bacteria. Their activity has led to antimicrobial peptides being considered as a first line of defense of multicellular organisms against microorganisms (1-3).

Plants, insects and animals produce these peptides. In the case of animals, AMPs are produced by cells from tissues exposed to pathogens. The destructive AMP action is rapid and occurs before the pathogen produces a major reaction through the body $(1,4)$. Microbes also produce AMPs which in turn limit the development of other microorganisms $(1,2)$. By extension, a number of bacterial toxins can be considered to be part of AMPs group (e.g. diphtheria toxin) $(2,5)$.

Structurally, constitutive or inducible AMPs are composed of amino acid residues, both hydrophilic and hydrophobic, and present a total positive charge (cationic). The hydrophobic regions alternate with the hydrophilic ones, generating the amphoteric character of the AMP molecules. The secondary structure includes four types: $\alpha$ helix (without disulfide bonds), $\beta$ folding, stabilized by 2 or more disulfide bonds, loop conformation, stabilized by a disulfide bond, and extended structure. The $\mathrm{N}$-terminus is rich in basic amino acids and the C-terminus in neutral, hydrophilic amino acids $(1,2,6)$.

The positive charge (cationic character) makes the interaction between the AMPs and the lipid bilayer of the negatively charged bacterial membrane possible; this process is followed by the membrane adsorption and, after that, by the destruction 
of the membrane, respectively, of the cell. The net cationic charge of AMPs is related to antibacterial activity and hydrophobicity to hemolytic activity. Other AMPs have the ability to cross the lipid layer, penetrating inside the cell, disrupting or inhibiting its functions, defined as the destruction of cellular organelles or DNA fragmentation $(1,2,6,7)$.

At present, 2272 AMPs have been identified in animals, and approximately 130 in humans (8).

In humans, there are several types of cells that can produce AMPs, but the most known are those produced in the skin: keratinocytes, eccrine cells, sebocytes; also, phagocytes and neutrophils produce significant amounts of AMP (8). Main AMPs produced in the skin are: Defensin, cathelicidin, S100A family of proteins, RNase 7 and dermcidine.

Defensin is the best known of AMPs, consisting of small cationic peptides, which are part of three subfamilies: $\alpha, \beta$ and circular. In humans, the most studied is the $\beta$-defensin family ( $\beta$-defensin-1/hBD1), found mainly in the respiratory epithelium, but not only; hBD2 and hBD3 are found in the upper layers of the epidermis of the normal skin and to a lesser extent in other types of epithelia, in which hBD4 predominates $(9,10)$. The production of defensins is stimulated by microbial lipopolysaccharides and also by proinflammatory cytokines. On the contrary, defensins stimulate the production of proinflammatory cytokines (IL-6, IL-10) and chemotactic factors. Defensins also stimulate the proliferation and migration of keratinocytes (9-11).

Cathelicidin (LL-37) is a member of a family of cationic AMPs, consisting of a chain of 37 amino acids, and it is inactive in keratinocytes, neutrophils, mast cells, eccrine gland cells, gastrointestinal epithelium. Enzymatic cleavage leads to the its active form, which manifests with a direct action of destroying the cell wall of microbes and fungi, and also with a very strong antiviral action $(11,12)$. LL-37 expression occurs following microbial stimulation, and also after the production of endogenous factors such as: Proinflammatory cytokines and active forms of vitamin $\mathrm{D}(12,13)$.

Without having its own receptor, LL-37 has an immunomodulatory effect being involved in inflammatory processes, acting as a chemo-attractant for neutrophils and macrophages, and inhibits neutrophil apoptosis, increasing phagocytosis (14). LL-37 has the ability to activate receptors on the cell surface, including toll-like receptors (TLR) and may act as an autoantigen $(15,16)$. It has been shown to contribute to different processes, such as wound healing, angiogenesis and tumor proliferation, in certain types of cancer (lung, prostate, squamous cell carcinoma, melanoma) (17).

The S100A7 protein, or psoriasin, a $11.7 \mathrm{kDa}$ protein, is part of the S100 protein family, and it is produced by keratinocytes. It was initially identified in psoriasis lesions, and, later, in healthy skin. Several members of this family are part of the corneal envelope of keratinocytes, developed by the activation of transglutaminase $(11,18,19)$. It has a strong antimicrobial action especially against $E$. coli $(20)$. S100A7 inhibits epidermal cell differentiation by increasing IL-6 production via the I $\kappa \mathrm{B} / \mathrm{NF}-\kappa \mathrm{B}$-induced signal (21). In cells of bronchial epithelium, TNF, IL-17, IL-22 massively increase the production of S100A7 (22). S100A7 protein can also activate activator protein 1 (AP1) or nuclear factor- $\kappa \mathrm{B}(\mathrm{NF}-\kappa \mathrm{B})(23)$. At the same time, interleukin-36 increases the production of LL-37, as well as S100A7, by activating NF- $\kappa \mathrm{B}(24)$. The S100A7 protein is associated with altered keratinocyte differentiation and may promote tumor cell migration, invasion, and metastasis, by promoting mesenchymal epithelial transition (25).

Ribonuclease 7 (RNase 7) is a member of the ribonucleases superfamily, formed by cationic peptides produced by immune cells, and also by epithelial tissue cells. These peptides have a strong antimicrobial, antifungal and antiviral activity, and also immunomodulatory activity $(26,27)$. RNase7 is produced by keratinocytes and is found at the level of stratum corneum and other types of epithelia. Bacterial products and also growth factors or cytokines induce the RNase production (28). RNase 7 is thought to have a pro-inflammatory role, but may selectively inhibit Th2 cytokines and may stimulate pDC (plasmacytoid dendritic cells) to recognize self-DNA $(29,30)$.

Dermcidin is an antimicrobial peptide, with a cationic structure, and it is produced by the sweat glands and eliminated by sweat, where it is found in large quantities. It has a strong antimicrobial action, creating ion channels in the membranes of bacterial cells. It seems to be involved in neural and tumor processes $(31,32)$.

\section{AMPs in innate immunity}

Currently AMPs are an important element of innate immunity through direct and immediate activation, with the destruction of pathogens.

In addition to this first function of innate immunity, they have a number of other functions, intervening at several levels of innate immunity. Thus, the action of destroying pathogens is coupled, in the case of AMPs, with a strong pro-inflammatory action, that occurs by coupling AMPs with various receptors (most importantly CCR6) on various immune or non-immune cells with increased production of pro-inflammatory cytokines. At the same time, AMPs have a strong chemo-attractant effect on many immune and non-immune cells, and also have the ability to act on cellular functions (differentiation, maturation, autophagy), or on the cell cycle (blocking apoptosis) as in the case of neutrophils $(8,32)$.

On the contrary, AMPs may, in some cases, induce an anti-inflammatory effect by inducing the secretion of anti-inflammatory cytokines. In essence, the activity of AMPs is pro-inflammatory, but in a certain context it may become anti-inflammatory (33).

It is not exactly known whether AMPs interact directly with TLR receptors, but it is demonstrated that they interact with a number of receptors such as: PRR, chemokine receptors (CCR2, CCR6), P2X7 receptors, epidermal growth factor receptors and NOD receptors $(8,33)$. Coupling with these receptors (many of them intracellular), induces transduction signals with the activation of numerous transcription factors: NF- $\kappa$ B, AP1, AP2, ERK and STAT3 (32).

Activation of the TLR receptors leads to the exacerbation of AMP production. Also, pro-inflammatory cytokines, especially IL-17, increase the production of AMP, especially defensin (34). Activation of TLR receptors by pathogen associated molecular pattern (PAMP) induces transduction signals in different cells with various effects. Intracellular TLR 3,7,8,9 are activated by nucleic acids that can most often come from the pathogen, but also from host cells due to cell destruction. Under certain conditions, self-nucleic acid may be accessible 
to TLRs. An example is IL-37 which has the ability to form nano-crystalline columnar complexes with various dsDNAs activating TLR9, inducing a strong transduction signal $(8,31)$.

Coupling LL-37 with self-DNA activates both TLR9 and pDC cells, with B lymphocytes and monocytes initiating the production of autoimmune processes. Defensin (hBD3) can bind to dsDNA in the same way as LL-37 and activates dendritic cells in infectious processes $(33,35)$.

Defensin hBD2 via the TLR4 pathway can also cause dendritic cell maturation by generating a Th1 response with cytotoxic T cell activation and NK (35).

Defensin, and to a greater extent LL-37, by their chemotaxis activation induce the production of cytokines and chemokines, the activation of dendritic cells as well as the polarization of $\mathrm{T}$ lymphocytes, achieving a functional link between innate immunity and adaptive immunity. Moreover, by acting in a certain biological context, AMP is an element of modulation of innate immunity over adaptive immunity (36).

\section{AMPs in psoriasis}

Psoriasis is an example of an inflammatory condition in which the relationship between keratinocyte (which proliferates aberrantly) and $\mathrm{T}$ lymphocyte, that maintains inflammation in the lesion, represents the basis of the pathogenic process (37). Keratinocytes confer the disease specificity and T lymphocytes contribute to development of lesions, and also affect other structures of the body. In the constitution of the pathogenic reaction, between keratinocyte and $\mathrm{T}$ lymphocyte, a series of pathogenic events are performed by biological structures, that are framed either in innate or adaptive immunity (38). AMP is an element of innate immunity, and plays an important role in the development of the pathogenic process in psoriasis. AMPs are initially involved in the early stages of this process. Keratinocytes, under the action of various traumatic factors, secrete AMP in excess which, in addition to antibiological activation, also have a strong proinflammatory action (chemokines, induction of cytokine secretion). One of the most important proinflammatory elements is the activation of dendritic cells (pDC, mDC), with massive secretion of IFN, TNF, the activation of neutrophils that secrete proinflammatory cytokines (IL-6, TNF $\alpha$ ) (39). Through the LL-37/self-DNA complexes there is stimulation of Th lymphocytes, then later Th1 and Th17 with the activation of the IL23/IL17 axis, but also with the stimulation by IL-17 of the secretion of AMP by keratinocytes. The action of AMP on TLR is unclear but TLR can induce AMP secretion (40).

\section{Conclusions}

AMPs play an important role in innate immunity, acting directly and indirectly on pathogens, being functionally integrated with most elements of innate immunity and exerting immunomodulatory action on adaptive immunity. AMPs participate in the main functions of innate immunity (direct action on pathogens, activation of inflammatory cells and tissue mediators, and action on adaptive immunity).

Psoriasis is a condition in which both types of immunity are involved in the pathogenic process. AMPs, as an element of innate immunity, are involved in the initiation and early stages of this process. The persistence of an increased amount of AMPs in psoriasis lesions orient towards a long-term action of AMPs in psoriasis.

\section{Acknowledgements}

Not applicable.

\section{Funding}

No funding was received.

\section{Availability of data and materials}

Not applicable.

\section{Authors' contributions}

MA analyzed the data from literature regarding the involvement of AMPs in psoriasis lesions and correctly introduced all the references according to the journal instructions. GC analyzed and wrote the main mechanisms of action of AMPs. AM designed the final aspect of the manuscript and wrote the conclusions. OAC analyzed and wrote the section on AMPs in innate immunity. All the authors critically revised the manuscript, and read and approved its final version.

\section{Ethics approval and consent to participate}

Not applicable.

\section{Patient consent for publication}

Not applicable.

\section{Competing interests}

The authors declare that they have no competing interests.

\section{References}

1. Bahar AA and Ren D: Antimicrobial peptides. Pharmaceuticals (Basel) 6: 1543-1575, 2013.

2. Zhang LJ and Gallo RL: Antimicrobial peptides. Curr Biol 26: R14-R19, 2016

3. Hoffmann J and Akira S: Innate immunity. Curr Opin Immunol 25: $1-3,2013$

4. Jones JD, Vance RE and Dangl JL: Intracellular innate immune surveillance devices in plants and animals. Science 354: aaf6395, 2016.

5. Jenssen H, Hamill P and Hancock RE: Peptide antimicrobial agents. Clin Microbiol Rev 19: 491-511, 2006.

6. Lei J, Sun L, Huang S, Zhu C, Li P, He J, Mackey V, Coy DH and $\mathrm{He} \mathrm{Q}$ : The antimicrobial peptides and their potential clinical applications. Am J Transl Res 11: 3919-3931, 2019.

7. Chen Y, Guarnieri MT, Vasil AI, Vasil ML, Mant CT and Hodges RS: Role of peptide hydrophobicity in the mechanism of action of alpha-helical antimicrobial peptides. Antimicrob Agents Chemother 51: 1398-1406, 2007.

8. Prasad SV, Fiedoruk K, Daniluk T, Piktel E and Bucki R: Expression and function of host defense peptides at inflammation sites. Int J Mol Sci 21: 104, 2019.

9. Weinberg A, Jin G, Sieg S and McCormick TS: The yin and yang of human beta-defensins in health and disease. Front Immunol 3: 294, 2012.

10. Pazgier M, Hoover DM, Yang D, Lu W and Lubkowski J: Human beta-defensins. Cell Mol Life Sci 63: 1294-1313, 2006. 
11. Marcinkiewicz M and Majewski S: The role of antimicrobial peptides in chronic inflammatory skin diseases. Postepy Dermatol Alergol 33: 6-12, 2016.

12. Kościuczuk EM, Lisowski P, Jarczak J, Strzałkowska N, Jóźwik A Horbańczuk J, Krzyżewski J, Zwierzchowski L and Bagnicka E: Cathelicidins: Family of antimicrobial peptides. A review. Mol Biol Rep 39: 10957-10970, 2012.

13. Vandamme D, Landuyt B, Luyten W and Schoofs L: A comprehensive summary of LL-37, the factotum human cathelicidin peptide. Cell Immunol 280: 22-35, 2012.

14. Agier J, Efenberger M and Brzezińska-Błaszczyk E: Cathelicidin impact on inflammatory cells. Cent Eur J Immunol 40: 225-235, 2015.

15. Agier J, Brzezińska-Błaszczyk E, Żelechowska P, Wiktorska M, Pietrzak J and Różalska S: Cathelicidin LL-37 affects surface and intracellular toll-like receptor expression in tissue mast cells. J Immunol Res 2018: 7357162, 2018.

16. Lande R, Botti E, Jandus C, Dojcinovic D, Fanelli G, Conrad C, Chamilos G, Feldmeyer L, Marinari B, Chon S, et al: The antimicrobial peptide LL37 is a T-cell autoantigen in psoriasis. Nat Commun 5: 5621, 2014.

17. Chen X, Zou X, Qi G, Tang Y, Guo Y, Si J and Liang L: Roles and mechanisms of human cathelicidin LL-37 in cancer. Cell Physiol Biochem 47: 1060-1073, 2018.

18. Eckert RL, Broome AM, Ruse M, Robinson N, Ryan D and Lee K: S100 proteins in the epidermis. J Invest Dermatol 123: 23-33, 2004.

19. Brodersen DE, Etzerodt M, Madsen P, Celis JE, Thøgersen HC, Nyborg $\mathrm{J}$ and Kjeldgaard M: EF-hands at atomic resolution: The structure of human psoriasin (S100A7) solved by MAD phasing. Structure 6: 477-489, 1998

20. Lee KC and Eckert RL: S100A7 (psoriasin)-mechanism of antibacterial action in wounds. J Invest Dermatol 127: 945-957, 2007.

21. Son ED, Kim HJ, Kim KH, Bin BH, Bae IH, Lim KM, Yu SJ, Cho EG and Lee TR: S100A7 (psoriasin) inhibits human epidermal differentiation by enhanced IL- 6 secretion through $\mathrm{I \kappa B} / \mathrm{NF}-\kappa \mathrm{B}$ signalling. Exp Dermatol 25: 636-641, 2016.

22. Hulse KA, Singh R and Chaung K: STAT3 and NF- $\kappa B$ regulate S100A7 expression in human bronchial epithelial cells. J Allergy Clin Immunol 129: AB68, 2012.

23. Águeda-Pinto A, Castro LFC and Esteves PJ: The evolution of S100A7: An unusual gene expansion in myotis bats. BMC Evol Biol 19: 102, 2019.

24. Nguyen TT, Niyonsaba F, Ushio H, Akiyama T, Kiatsurayanon C, Smithrithee R, Ikeda S, Okumura K and Ogawa $\mathrm{H}$ : Interleukin-36 cytokines enhance the production of host defense peptides psoriasin and LL-37 by human keratinocytes through activation of MAPKs and NF- $\kappa$ B. J Dermatol Sci 68: 63-66, 2012.

25. Tian T, Li X, Hua Z, Ma J, Wu X, Liu Z, Chen H and Cui Z: S100A7 promotes the migration, invasion and metastasis of human cervical cancer cells through epithelial-mesenchymal transition. Oncotarget 8: 24964-24977, 2017.

26. Becknell B and Spencer JD: A review of ribonuclease 7's structure, regulation, and contributions to host defense. Int $\mathrm{J}$ Mol Sci 17: 423, 2016 .
27. Schwartz L, Cohen A, Thomas J and Spencer JD: The immunomodulatory and antimicrobial properties of the vertebrate ribonuclease a superfamily. Vaccines (Basel) 6: 76, 2018.

28. Kopfnagel V, Wagenknecht S, Brand L, Zeitvogel J, Harder J, Hofmann K, Kleine $M$ and Werfel T: RNase 7 downregulates $\mathrm{TH} 2$ cytokine production by activated human T cells. Allergy 72 : 1694-1703, 2017.

29. Kopfnagel V, Wagenknecht S, Harder J, Hofmann K, Kleine M, Buch A, Sodeik B and Werfel T: RNase 7 strongly promotes TLR9-mediated DNA sensing by human plasmacytoid dendritic cells. J Invest Dermatol 138: 872-881, 2018.

30. Paulmann M, Arnold T, Linke D, Özdirekcan S, Kopp A, Gutsmann T, Kalbacher H, Wanke I, Schuenemann VJ, Habeck M, et al: Structure-activity analysis of the dermcidin-derived peptide DCD-1L, an anionic antimicrobial peptide present in human sweat. J Biol Chem 287: 8434-8443, 2012.

31. Schittek B: The multiple facets of dermcidin in cell survival and host defense. J Innate Immun 4: 349-360, 2012.

32. Sun E, Belanger CR, Haney EF and Hancock RE: Host defense (antimicrobial) peptides. Computational And Systems Biol 10 253-285, 2018.

33. Lee EY, Lee MW and Wong GCL: Modulation of toll-like receptor signaling by antimicrobial peptides. Semin Cell Dev Biol 88: 173-184, 2019.

34. Kao CY, Chen Y, Thai P, Wachi S, Huang F, Kim C, Harper RW and Wu R: IL-17 markedly up-regulates beta-defensin-2 expression in human airway epithelium via JAK and NF-kappaB signaling pathways. J Immunol 173: 3482-3491, 2004.

35. Schmidt N, Jin F, Lande R, Curk T, Xian W, Lee C, Frasca L, Frenkel D, Dobnikar J, Gilliet M and Wong GC: Liquid-crystalline ordering of antimicrobial peptide-DNA complexes controls TLR9 activation. Nat Mater 14: 696-700, 2015.

36. Choi KY and Mookherjee N: Multiple immune-modulatory functions of cathelicidin host defense peptides. Front Immunol 3: 149,2012

37. Boehncke WH and Schön MP: Psoriasis. Lancet 386: 983-994, 2015.

38. Mahil SK, Capon F and Barker JN: Update on psoriasis immunopathogenesis and targeted immunotherapy. Semin Immunopathol 38: 11-27, 2016.

39. Gottlieb AB, Lebwohl M, Shirin S, Sherr A, Gilleaudeau P, Singer G, Solodkina G, Grossman R, Gisoldi E, Phillips S, et al: Anti-CD4 monoclonal antibody treatment of moderate to severe psoriasis vulgaris: Results of a pilot, multicenter, multiple-dose, placebo-controlled study. J Am Acad Dermatol 43: 595-604, 2000.

40. Di Cesare A, Di Meglio P and Nestle FO: The IL-23/Th17 axis in the immunopathogenesis of psoriasis. J Invest Dermatol 129: $1339-1350,2009$ 